\title{
An Integrated Multi-Attribute-Decision Making Approach for Selecting Structural System: A Case Study
}

\author{
Gul Polat ${ }^{\mathrm{a}, *}$, Harun Turkoglu ${ }^{\mathrm{b}}$, Atilla Damci ${ }^{\mathrm{c}}$ \\ ${ }^{a}$ Professor, Istanbul Technical Universiy, Istanbul 34469, Turkey \\ ${ }^{b}$ Research Assistant, Istanbul Technical Universiy, Istanbul 34469, Turkey \\ ${ }^{c}$ Associate Professor, Istanbul Technical Universiy, Istanbul 34469, Turkey
}

\begin{abstract}
A structural system is the essential component of a building, which carries all loads acting on the building and transfers them effectively to the soil through the foundation. The design team, which includes engineers and architects, is in charge of determining the most appropriate structural system that will fulfill the owner's and end user's requirements as well as the legal requirements. Selecting the most appropriate structural system is a difficult task as there are many factors that need to be taken into consideration. Therefore, this problem can be considered as a multi-attribute-decision-making (MADM) process. This study proposes an integrated MADM approach for solving this problem, which uses the analytic hierarchy process (AHP) and Vise Kriterijumska Optimizacija I Kompromisno Resenje (VIKOR) methods. In the proposed approach, AHP is used to find the weights of the criteria and VIKOR is used to rank the alternatives. The proposed approach was employed in a real case. Extensive review of the relevant literature was carried out and the face to face interviews were conducted with four engineers of the design team, which was responsible for the selection process of structural system in the studied case, in order to identify the criteria that may affect the selection of a structural system from the managerial perspective. A total of 5 main criteria, namely the durability and safety of the project, the energy consumption, the project characteristics, the total cost, and the constructability problems, and 19 corresponding sub-criteria were identified. The findings of this study revealed that the proposed approach can be a useful tool in selecting a structural system.
\end{abstract}

(C) 2018 The Authors. Published by Diamond Congress Ltd., Budapest University of Technology and Economics Peer-review under responsibility of the scientific committee of the Creative Construction Conference 2018.

Keywords: AHP;VIKOR; multi-attribute-decision making; structural system selection; case study.

\section{Introduction}

A structural system must be able to perform the task of carrying all loads and transferring them safely to the soil through the foundation. Selection of the structural system, which can be considered as the skeleton of the structure, is one of the most important decisions as it determines the future of the structure [1]. In general, safety and aesthetics of a constructed facility depends on the selection of the structural system, which is selected by the design team, which includes engineers and architects [2]. The design team aims to determine the most appropriate structural system that will fulfill the owner's and users' requirements as well as the legal requirements $[1,3]$.

In building projects, different material alternatives can be preferred in structural systems such as reinforced concrete, steel, precast, masonry, wood, composite, etc. Each material has pros and cons. For example, while wood buildings are light and relatively cheap, reinforced concrete buildings can resist wind loads, and steel structures allow large spans and resist seismic loads. Consequently, selecting an appropriate structural system is a difficult task as there are many factors that need to be taken into consideration [1,4-6]. 
The objective of this study is to propose an integrated MADM approach for selecting the appropriate structural systems. For this purpose, first, an extensive literature review was carried out in order to determine the factors that may affect the selection of a structural system from the managerial perspective. After that, an integrated approach was proposed in order to assist the owner and design team in selecting the structural system from the managerial viewpoint. In the proposed approach, AHP is used to find the weights of the criteria and VIKOR is used to rank the alternatives. In order to illustrate how the proposed integrated approach can be applied in a real life project, a case study was carried out. The findings of this study revealed that the proposed integrated model can be used a useful tool in selection of the most appropriate structural system to make sound and reasonable decisions.

\section{The Proposed Approach}

The proposed approach includes eight steps, which can be classified under two main stages. The steps of the proposed approach are presented in Fig. 1.

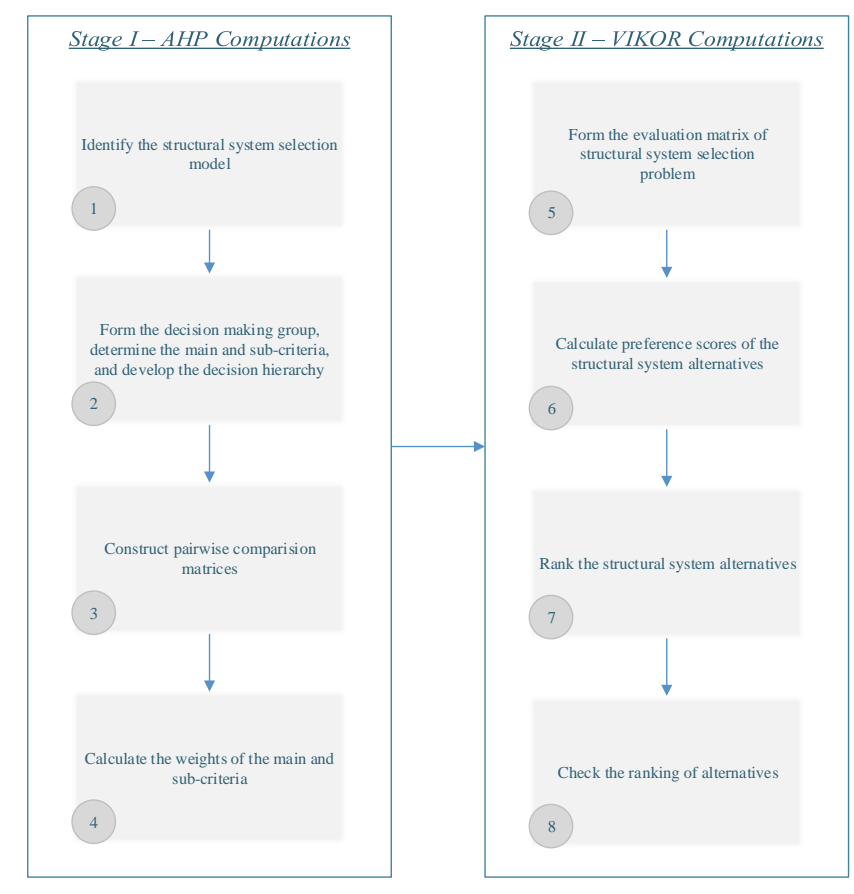

Fig. 1. The steps of the proposed approach.

In the first stage, the structural system selection problem is identified. Then, the decision making group, who are in charge of structural system selection in the construction company, is formed, and this group determines the main and sub-criteria that may affect the structural system selection and develops the hierarchy of the structural system selection model. Thirdly, the decision making group constructs pairwise comparison matrices of the structural system selection problem. In the final step of the first stage, the weights of the main and sub-criteria of the structural system selection problem are calculated by using the AHP method. In the second stage, first, the evaluation matrix, which consists of the assessments of the decision-making group members on the alternative structural systems, is formed. In the second step, the preference scores of the structural system alternatives are calculated by using the VIKOR method. Then, the structural system alternatives are ranked based on their preference scores in a descending order. Finally, the ranking of the alternatives is checked whether it meets the conditions of the VIKOR method.

\subsection{Analytical Hierarchy Process (AHP)}

The AHP is a mathematical theory developed by Thomas L. Saaty in 1980 to solve complex decision-making problems. AHP allows decision makers to model complex problems in a hierarchical structure that demonstrates the relationships among the problem's goal, main criteria, sub-criteria, and alternatives [7]. Since AHP is easy to 
understand by decision makers, it has been widely used in the literature and has been performed in almost all applications for multi-attribute-decision making in the last 35 years. AHP enables both objective and subjective opinions to be included in the decision-making process [8]. The calculation steps of AHP are explained below [9,10]:

Step 1: Defining the hierarchical structure of the decision problem (i.e., goal, main criteria, sub-criteria, alternatives).

Step 2: Constructing pairwise comparison matrices that allows numerical representations of relations between two elements in the hierarchy by using Saaty's Rating Scale (see Table 1).

Step 3: Calculating the consistency ratio indicating whether the matrices generated are consistent.

Step 4: Finding the priorities of the alternatives according to the main criteria and/or sub-criteria.

Table 1. Saaty's Rating Scale.

\begin{tabular}{lll}
\hline Intensity of importance & Definition & Explanation \\
\hline 1 & Equal importance & Two factors contribute equally to the objective. \\
3 & Somewhat more important & Experience and judgment slightly favor one over the other. \\
5 & Much more important & Experience and judgment strongly favor one over the other. \\
7 & Very much important & Experience and judgment very strongly favor one over the other. \\
9 & Absolutely more important & The evidence favoring one over the other is one of the highest possible validity. \\
$2,4,6,8$ & Intermediate values & When compromise is needed. \\
\hline
\end{tabular}

\subsection{Vise Kriterijumska Optimizacija I Kompromisno Resenje (VIKOR)}

VIKOR method was developed by Opricovic and Tzeng in 2004 as a multi-attribute-decision making method to solve certain decision problems that are not measured by the same unit and have contradictory criteria. The method is an effective tool in multi-attribute-decision making, particularly in a situation where the decision maker is not able, or does not know to express its preference at the beginning of system design. This method provides compromise solutions for problems with contradictory criteria, by focusing on ranking and selecting on a set of specific alternatives. In this way, the method helps the decision makers to reach the final decision [11]. Compromise solution is obtained under the assumption that each alternative is evaluated for each criterion by comparing the values of proximity to the ideal solution. VIKOR method considers maximum group utility and minimum individual regret. The calculation steps of the method are quite simple and clear, which are briefly explained below [12]:

Step 1: Constructing the evaluation matrix $X$ with $n$ number of alternatives $(\mathrm{n}=1, \ldots \ldots, i)$ and $m$ number of criteria $(\mathrm{m}=1, \ldots . ., j)$.

Step 2: Identifying the positive ideal solutions of $n$ alternatives according to each criterion $j\left(f_{j}^{*}\right)$ and the negative ideal solutions of $n$ alternatives according to each criterion $j\left(f_{j}^{-}\right)$.

Step 3: Normalizing the elements of the evaluation matrix.

Step 4: Computing $S_{i}$ (the maximum group utility, which is the distance between alternative $i$ and the positive ideal solution $f_{j}^{*}$ ) and $R_{i}$ (the minimum individual regret of the opponent, which is the distance between alternative $i$ and the negative ideal solution $f_{j}^{-}$).

Step 5: Computing $Q_{i}$ (the VIKOR index for each alternative $i$, which is computed using the weight of the strategy of the maximum group utility $q$ ).

Step 6: Ranking the alternatives, sorting by the values of $Q_{i}$, in decreasing order.

Step 7: Proposing as a compromise solution the alternative $\left(A_{I}\right)$, which is ranked the best by the measure $Q_{i}$ (minimum), if the following two conditions are satisfied:

Condition 1. "Acceptable advantage"

$$
Q\left(A_{2}\right)-Q\left(A_{1}\right) \geq \frac{1}{n-1}
$$

where $A_{2}$ is the alternative with the second position in the ranking list by $Q_{i} ; n$ is the number of alternatives. 
Condition 2. "Acceptable stability in decision making"

Alternative $A_{l}$ must also be the best ranked by $S_{i}$ or/and $R_{i}$. This compromise solution is stable within a decision making process, which could be: "voting by majority rule" (when $q>0.5$ is needed), or by consensus" ( $q \approx 0.5$ ), or "with veto" $(q<0.5)$.

If one of the conditions is not satisfied, then a set of compromise solutions is proposed, which consists of:

- Alternatives $A_{1}$ and $A_{2}$ if only Condition 2 is not satisfied, or

- Alternatives $A_{1}, A_{2}, \ldots, A_{K}$ if Condition 1 is not satisfied; and $A_{K}$ is determined by using Equation 2 for maximum $K$.

$$
Q\left(A_{K}\right)-Q\left(A_{1}\right) \approx \frac{1}{n-1}
$$

The best alternative is the one with the minimum value of $Q_{i}$. The main ranking result is the compromise ranking list of alternatives, and the compromise solution with the "advantage rate".

\section{Case Study: Selecting the Most Appropriate Structural System}

The proposed integrated structural system selection model was applied in a real case, which is a housing project in Istanbul, Turkey. This project consists of 3 basement floors, a ground floor, and 3 normal floors, and total construction area is $822,000 \mathrm{~m}^{2}$. The structural system was selected based on the knowledge and experience of the design team, thus all of four civil engineers, who were responsible for the structural system selection, participated in developing this model. The model was developed based on their opinions and evaluations.

\subsection{Decision Hierarchy of the Structural System Selection Problem}

Having conducted face-to-face interviews with the design team members and carried out an extensive review of literature, 5 main criteria have been identified, which include: durability and safety $(D S)$, energy consumption $(E C)$, project characteristics $(P C)$, total cost $(T C)$, and constructability problems $(C P)$. 5 sub-criteria under the main criterion $D S$ are: resistance to external conditions $\left(D S_{1}\right)$, resistance to seismic loads $\left(D S_{2}\right)$, safety against fire $\left(D S_{3}\right)$, resistance to wind loads $\left(D S_{4}\right)$, and lifecycle of the structure $\left(D S_{5}\right) .3$ sub-criteria under the main criterion $E C$ include: energy used to construct the structural system $\left(E C_{1}\right)$, production energy of construction materials $\left(E C_{2}\right)$, and reusability of construction materials $\left(E C_{3}\right) .6$ sub-criteria under the main criterion $P C$ are: the number of floors $\left(P C_{1}\right)$, need for large spans in the structure $\left(P C_{2}\right)$, need for huge amount of clear space $\left(P C_{3}\right)$, aesthetics of the structure $\left(P C_{4}\right)$, changeability of the internal space $\left(P C_{5}\right)$, and modularity of the structure $\left(P C_{6}\right) .2$ sub-criteria under the main criterion $T C$ include: construction cost of the project $\left(T C_{l}\right)$ and operation and maintenance costs of the project $\left(T C_{2}\right) .3$ sub-criteria under the main criterion $D C$ are: construction duration $\left(D C_{1}\right)$, delivery of construction materials to the site $\left(D C_{2}\right)$, and availability of laborers and equipment $\left(D C_{3}\right)$. The design team identified four different structural system alternatives, which are: reinforced concrete $(A 1)$, steel structure $(A 2)$, composite structure $(A 3)$, and precast construction (A4). The decision hierarchy of the structural system selection problem is presented in Fig. 2.

\subsection{Determining the Weights of the Main and Sub-criteria of the Selection Problem}

After constructing the decision hierarchy of the structural system selection problem, the AHP method is used to determine the weights of the identified main criteria and sub-criteria. For that reason, four decision makers were asked individually to construct pairwise comparison matrices for the main and sub-criteria of the selection problem. Four pairwise comparison matrices were then aggregated by taking the geometric means of each preference in order to reach a group decision. Finally, the mathematical calculations of the AHP method were applied to find the weights of the main and sub-criteria of the selection problem. 


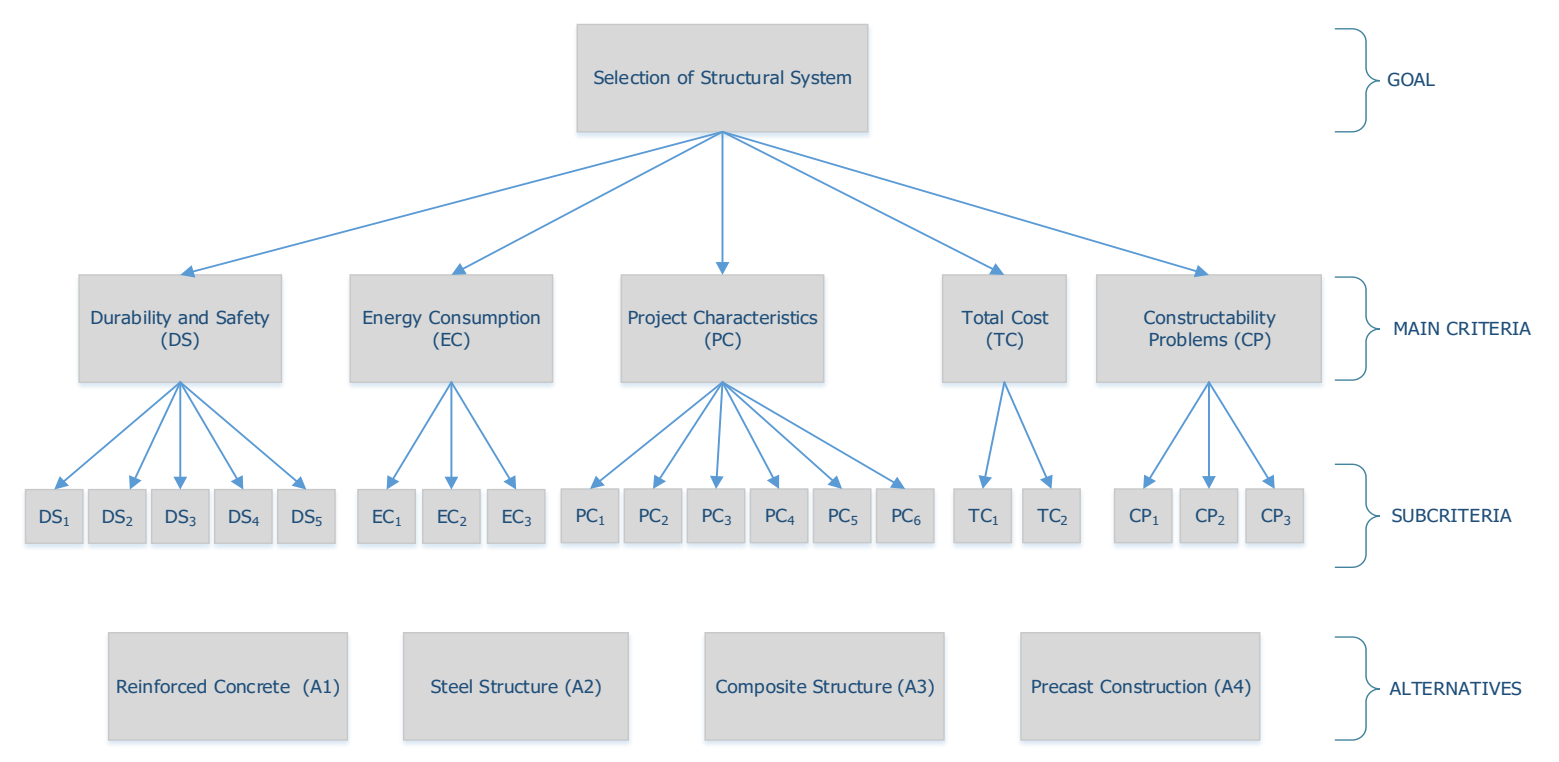

Fig. 2. Decision hierarchy of the structural system selection problem

Table 2 shows the weights of main criteria of the appropriate structural system selection problem.

Table 2. Aggregated pairwise matrix of main criteria for the structural system selection problem.

\begin{tabular}{|c|c|c|c|c|c|c|}
\hline Criteria & DS & $\mathrm{EC}$ & PC & $\mathrm{TC}$ & $\mathrm{CP}$ & Weights \\
\hline DS & 1.00 & 2.38 & 1.68 & 2.06 & 2.38 & 0.34 \\
\hline $\mathrm{EC}$ & 0.42 & 1.00 & 0.64 & 1.07 & 1.00 & 0.15 \\
\hline PC & 0.59 & 1.57 & 1.00 & 1.57 & 1.57 & 0.22 \\
\hline TC & 0.49 & 0.93 & 0.64 & 1.00 & 1.19 & 0.15 \\
\hline CP & 0.42 & 1.00 & 0.64 & 0.84 & 1.00 & 0.14 \\
\hline
\end{tabular}

According to the findings, the "DS-Durability and Safety" has the highest weight on the selection of a structural system problem. It is followed by the "PC-Project Characteristics" with second higher weight. On the other hand, the "CP-Constructability Problems" has the least importance on the selection process as it has the lowest weight. The consistency ratio (C.R.) of the aggregated pairwise comparison matrix is also checked. Since it is below the 0.10, it can be concluded that the evaluations are consistent.

The aggregated pairwise comparison matrix of five sub-criteria identified under the "DS-Durability and Safety" criterion is given in Table 3 .

Table 3. Aggregated pairwise matrix of sub-criteria for the "DS-Durability and Safety".

\begin{tabular}{|c|c|c|c|c|c|c|}
\hline Sub-Criteria & $\mathrm{DS}_{1}$ & $\mathrm{DS}_{2}$ & $\mathrm{DS}_{3}$ & $\mathrm{DS}_{4}$ & $\mathrm{DS}_{5}$ & Weights \\
\hline $\mathrm{DS}_{1}$ & 1.00 & 0.45 & 1.41 & 2.21 & 1.68 & 0.20 \\
\hline $\mathrm{DS}_{2}$ & 2.21 & 1.00 & 2.83 & 4.76 & 4.00 & 0.44 \\
\hline $\mathrm{DS}_{3}$ & 0.71 & 0.35 & 1.00 & 1.68 & 1.28 & 0.15 \\
\hline $\mathrm{DS}_{4}$ & 0.45 & 0.21 & 0.59 & 1.00 & 0.76 & 0.09 \\
\hline $\mathrm{DS}_{5}$ & 0.59 & 0.25 & 0.78 & 1.32 & 1.00 & 0.12 \\
\hline
\end{tabular}

Based on the findings, the " $D S_{2}$ - Resistance to seismic loads" has the highest weight among all sub-criteria. The aggregated matrix is also consistent (C.R. $=0.0004<0.1)$.

The aggregated pairwise comparison matrix of three sub-criteria of the "EC- Energy Consumption" criterion is given in Table 4. 
Table 4. Aggregated pairwise matrix of sub-criteria for the "EC- Energy Consumption".

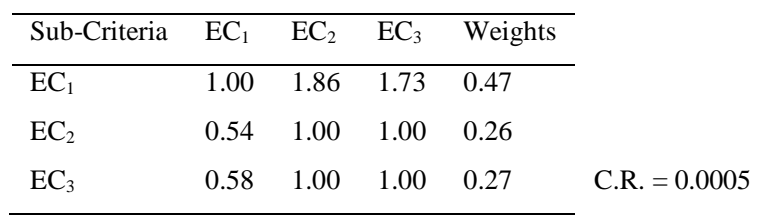

Based on the findings, the " $E C_{1^{-}}$Energy used to construct the structural system" has the highest weight. The aggregated matrix is also consistent since the consistency ratio is less than 0.1 .

The aggregated pairwise comparison matrix of six sub-criteria for the " $P C$ - Project Characteristics" criterion is presented in Table 5.

Table 5. Aggregated pairwise matrix of sub-criteria for the " $P C$ - Project Characteristics".

\begin{tabular}{|c|c|c|c|c|c|c|c|}
\hline Sub-Criteria & $\mathrm{PC}_{1}$ & $\mathrm{PC}_{2}$ & $\mathrm{PC}_{3}$ & $\mathrm{PC}_{4}$ & $\mathrm{PC}_{5}$ & $\mathrm{PC}_{6}$ & Weights \\
\hline $\mathrm{PC}_{1}$ & 1.00 & 1.41 & 2.28 & 2.45 & 2.06 & 2.71 & 0.29 \\
\hline $\mathrm{PC}_{2}$ & 0.71 & 1.00 & 1.86 & 1.86 & 1.57 & 2.21 & 0.22 \\
\hline $\mathrm{PC}_{3}$ & 0.44 & 0.54 & 1.00 & 1.00 & 0.84 & 1.19 & 0.12 \\
\hline $\mathrm{PC}_{4}$ & 0.41 & 0.54 & 1.00 & 1.00 & 0.84 & 1.19 & 0.12 \\
\hline $\mathrm{PC}_{5}$ & 0.49 & 0.64 & 1.19 & 1.19 & 1.00 & 1.41 & 0.14 \\
\hline $\mathrm{PC}_{6}$ & 0.37 & 0.45 & 0.84 & 0.84 & 0.71 & 1.00 & 0.10 \\
\hline
\end{tabular}

Based on the findings, the " $P C_{l^{-}}$The number of floors" has the highest weight. The aggregated matrix is also consistent $($ C.R. $=0.0003<0.1)$.

The aggregated pairwise comparison matrix of two sub-criteria identified under the " $T C$-Total cost" criterion is given in Table 6.

Table 6. Aggregated pairwise matrix of sub-criteria for the "TC-Total cost".

\begin{tabular}{lllll}
\hline Sub-Criteria & $\mathrm{TC}_{1}$ & $\mathrm{TC}_{2}$ & Weights & \\
\cline { 1 - 4 } $\mathrm{TC}_{1}$ & 1.00 & 1.41 & 0.59 & \\
$\mathrm{TC}_{2}$ & 0.71 & 1.00 & 0.41 & C.R. $=0.0000$ \\
\cline { 1 - 4 } & & & &
\end{tabular}

Based on the findings, the " $C_{l^{-}}$Construction cost of the project" has the highest weight. The aggregated matrix is also consistent since the consistency ratio is less than 0.1 .

The aggregated pairwise comparison matrix of three sub-criteria of the " $C P$-Constructability problems" is presented in Table 7.

Table 7. Aggregated pairwise matrix of sub-criteria for the " $C P$-Constructability problems".

\begin{tabular}{llllll}
\cline { 1 - 4 } Sub-Criteria & $\mathrm{CP}_{1}$ & $\mathrm{CP}_{2}$ & $\mathrm{CP}_{3}$ & Weights & \\
\cline { 1 - 5 } $\mathrm{CP}_{1}$ & 1.00 & 2.83 & 3.72 & 0.62 & \\
$\mathrm{CP}_{2}$ & 0.35 & 1.00 & 1.32 & 0.22 & \\
$\mathrm{CP}_{3}$ & 0.27 & 0.76 & 1.00 & 0.17 & C.R. $=0.0000$
\end{tabular}

Based on the findings, the "CP$P_{1}$-Construction duration" has the highest weight. The aggregated matrix is also consistent (C.R. $=0.0000<0.1)$.

\subsection{Finding the Preferences of the Structural System Alternatives with VIKOR Method}

After determining the weights of the main criteria and sub-criteria of the structural system selection problem, VIKOR method was employed to determine the ranking of four structural system alternatives. In the structural 
system selection problem, the preferences of four decision makers were collected to form the decision matrix. The data of "construction cost of the project" $\left(T C_{l}\right)$ is quantitative and measured in Turkish Lira, whereas the other subcriteria are qualitative and these values were obtained using 1 to 9 point scale (i.e., 1: Very Bad; 9: Very Good).

In order to construct an aggregated decision matrix of the structural system selection problem, geometric means of the individual evaluations of the decision makers on the alternatives were calculated (see Table 8). In this selection problem, $C_{1}$ and $C_{2}$ are cost criteria where the smaller value is always preferred. The rest of them are beneficial criteria where the larger values are desirable. Therefore, $T C_{1}$ and $T C_{2}$ are minimized and the rest are maximized.

Table 8. Aggregated decision matrix of evaluation criteria for four structural system alternatives.

\begin{tabular}{|c|c|c|c|c|c|c|c|}
\hline Criteria & Unit & $\begin{array}{l}\text { Reinforced Concrete } \\
\text { (A1) }\end{array}$ & Steel Structure (A2) & $\begin{array}{l}\text { Composite Structure } \\
\text { (A3) }\end{array}$ & $\begin{array}{l}\text { Precast Construction } \\
\text { (A4) }\end{array}$ & Weight & $\begin{array}{l}\text { Opt. } \\
\text { Dir. }\end{array}$ \\
\hline $\mathrm{DS}_{1}$ & S.S & 7.11 & 4.74 & 5.24 & 6.59 & 0.07 & $\uparrow$ \\
\hline $\mathrm{DS}_{2}$ & S.S & 7.97 & 7.20 & 5.66 & 3.98 & 0.15 & $\uparrow$ \\
\hline $\mathrm{DS}_{3}$ & S.S & 6.88 & 2.74 & 2.89 & 5.57 & 0.05 & $\uparrow$ \\
\hline $\mathrm{DS}_{4}$ & S.S & 8.21 & 4.21 & 5.96 & 6.12 & 0.03 & $\uparrow$ \\
\hline $\mathrm{DS}_{5}$ & S.S & 6.40 & 7.20 & 5.23 & 4.86 & 0.04 & $\uparrow$ \\
\hline $\mathrm{EC}_{1}$ & S.S & 7.48 & 6.40 & 6.40 & 5.89 & 0.07 & $\uparrow$ \\
\hline $\mathrm{EC}_{2}$ & S.S & 5.89 & 7.17 & 6.90 & 6.16 & 0.04 & $\uparrow$ \\
\hline $\mathrm{EC}_{3}$ & S.S & 2.99 & 6.88 & 5.69 & 4.46 & 0.04 & $\uparrow$ \\
\hline $\mathrm{PC}_{1}$ & S.S & 6.09 & 6.45 & 4.56 & 6.16 & 0.06 & $\uparrow$ \\
\hline $\mathrm{PC}_{2}$ & S.S & 5.38 & 7.97 & 4.90 & 7.14 & 0.05 & $\uparrow$ \\
\hline $\mathrm{PC}_{3}$ & S.S & 6.74 & 4.74 & 8.00 & 7.97 & 0.03 & $\uparrow$ \\
\hline $\mathrm{PC}_{4}$ & S.S & 6.59 & 7.17 & 6.85 & 5.96 & 0.03 & $\uparrow$ \\
\hline $\mathrm{PC}_{5}$ & S.S & 5.21 & 4.24 & 4.05 & 3.98 & 0.03 & $\uparrow$ \\
\hline $\mathrm{PC}_{6}$ & S.S & 1.86 & 5.58 & 5.18 & 6.59 & 0.02 & $\uparrow$ \\
\hline $\mathrm{TC}_{1}$ & $\mathrm{x} 10^{3} \mathrm{TL}$ & 335 & 795 & 650 & 720 & 0.09 & $\downarrow$ \\
\hline $\mathrm{TC}_{2}$ & S.S & 4.16 & 7.90 & 6.05 & 5.24 & 0.06 & $\downarrow$ \\
\hline $\mathrm{CP}_{1}$ & S.S & 5.00 & 7.09 & 6.62 & 6.51 & 0.09 & $\uparrow$ \\
\hline $\mathrm{CP}_{2}$ & S.S & 6.51 & 5.63 & 5.38 & 4.68 & 0.03 & $\uparrow$ \\
\hline $\mathrm{CP}_{3}$ & S.S & 7.33 & 5.38 & 5.48 & 4.95 & 0.02 & $\uparrow$ \\
\hline
\end{tabular}

After forming the aggregated decision matrix, the steps of VIKOR method were followed. First, the best $f_{j}^{*}$ and the worst $f_{j}^{-}$values of all criteria were determined (see Table 9).

Table 9. Aggregated decision matrix of evaluation criteria for the four structural system alternatives.

\begin{tabular}{|c|c|c|c|c|c|c|c|c|c|c|c|c|c|c|c|c|c|c|c|}
\hline & $\mathrm{DS}_{1}$ & $\mathrm{DS}_{2}$ & $\mathrm{DS}_{3}$ & $\mathrm{DS}_{4}$ & $\mathrm{DS}_{5}$ & $\mathrm{EC}_{1}$ & $\mathrm{EC}_{2}$ & $\mathrm{EC}_{3}$ & $\mathrm{PC}_{1}$ & $\mathrm{PC}_{2}$ & $\mathrm{PC}_{3}$ & $\mathrm{PC}_{4}$ & $\mathrm{PC}_{5}$ & $\mathrm{PC}_{6}$ & $\mathrm{C}_{1}$ & $\mathrm{C}_{2}$ & $\mathrm{DC}_{1}$ & $\mathrm{DC}_{2}$ & $\mathrm{DC}_{3}$ \\
\hline RCC & 7.11 & 7.97 & 6.88 & 8.21 & 6.40 & 7.48 & 5.89 & 2.99 & 6.09 & 5.38 & 6.74 & 6.59 & 5.21 & 1.86 & 335.00 & 4.16 & 5.00 & 6.51 & 7.33 \\
\hline SS & 4.74 & 7.20 & 2.74 & 4.21 & 7.20 & 6.40 & 7.17 & 6.88 & 6.45 & 7.97 & 4.74 & 7.17 & 4.24 & 5.58 & 795.00 & 7.90 & 7.09 & 5.63 & 5.38 \\
\hline $\mathrm{CS}$ & 5.24 & 5.66 & 2.89 & 5.96 & 5.23 & 6.40 & 6.90 & 5.69 & 4.56 & 4.90 & 8.00 & 6.85 & 4.05 & 5.18 & 650.00 & 6.05 & 6.62 & 5.38 & 5.48 \\
\hline PC & 6.59 & 3.98 & 5.57 & 6.12 & 4.86 & 5.89 & 6.16 & 4.36 & 6.16 & 7.14 & 7.97 & 5.96 & 3.98 & 6.59 & 720.00 & 5.24 & 6.51 & 4.68 & 4.95 \\
\hline$f_{i}^{*}$ & 7.11 & 7.97 & 6.88 & 8.21 & 7.20 & 7.48 & 7.17 & 6.88 & 6.45 & 7.97 & 8.00 & 7.17 & 5.21 & 6.59 & 335.00 & 4.16 & 7.09 & 6.51 & 7.33 \\
\hline$f_{i}^{-}$ & 4.74 & 3.98 & 2.74 & 4.21 & 4.86 & 5.89 & 5.89 & 2.99 & 4.56 & 4.90 & 4.74 & 5.96 & 3.98 & 1.86 & 795.00 & 7.90 & 5.00 & 4.68 & 4.95 \\
\hline
\end{tabular}

Then, the normalized decision matrix was computed. After that, the values $S_{i}, R_{i}$, and $Q_{i}$ of four structural system alternatives were calculated. Finally, four structural system alternatives were ranked by $Q_{i}$ values in decreasing order. The result matrix is shown in Table 10. 
Table 10. Result matrix of VIKOR method.

\begin{tabular}{lllllll}
\hline Alternatives & $\mathrm{S}_{\mathrm{i}}$ & $\mathrm{R}_{\mathrm{i}}$ & $\mathrm{Q}_{\mathrm{i}}$ & Ranking & Checking Conditions & \\
\hline $\mathrm{A} 1$ & 0.276 & 0.086 & 0.000 & 1.00 & $\mathrm{C} 1.0 .309<0.333$ & $\mathbf{x}$ \\
$\mathrm{A} 2$ & 0.469 & 0.089 & 0.309 & 2.00 & $\mathrm{C} 2 . \mathrm{A} 1\left(R_{i}\right)=\min \left(R_{i}\right)$ & $\checkmark$ \\
$\mathrm{A} 3$ & 0.614 & 0.087 & 0.507 & 3.00 & & \\
$\mathrm{~A} 4$ & 0.614 & 0.150 & 1.000 & 4.00 & & \\
\hline
\end{tabular}

Based on the ranking results, although A1 (reinforced concrete construction) is the best alternative with minimum $Q_{i}$ value, A1 and A2 (steel structure) are compromise solutions because A1 does not satisfy the "acceptable advantage" condition. According to the ranking results, A3 (composite structure) and A4 (precast construction) ranked third and fourth, respectively. The outcomes of proposed model were discussed with the decision makers and the construction company preferred A1 as the structural system in real life. They stated that they had mostly selected the structural system based on one single criterion, namely cost, and had not considered other factors. They concluded that they could employ the proposed model in future to make sound decisions.

\section{Conclusions}

Selection of an appropriate structural system is a difficult task in design phase as there are many factors that need to be taken into consideration. An extensive literature review was carried out in order to identify the factors that may affect the selection of a structural system from the managerial perspective. This study proposed an integrated model for selecting the most appropriate structural system. Two multi-attribute-decision-making methods, namely AHP and VIKOR, were integrated to find the most appropriate structural system option among the alternatives. In the integrated model, the AHP method was used to determine the weights of the identified main criteria and their constituent sub-criteria. The VIKOR method was used to determine the ranking of the structural system alternatives. In order to demonstrate how the proposed integrated approach can be performed in a real life project, a case study was carried out. The finding of the proposed integrated model was discussed with the decision makers, who participated in this study. This study revealed that the proposed integrated model can be utilized as a guideline in selecting the most appropriate structural system from the managerial viewpoint.

\section{References}

[1] AlShamrani, O. S., Selection of Structural Systems and Materials: Minimizing Lateral Drift and Cost of Tall Buildings in Saudi Arabia, Doctoral dissertation, University of Southern California, (2007).

[2] Chen, W. F., \& Lui, E. M. (Eds.), Principles of Structural Design, CRC Press, (2005).

[3] Alzuhairy, S.H., Stuructural system of high rise and long span building, 2015, Retrieved from cihanuniversity.edu.iq/files/1429475958.pdf, on February 14, 2018.

[4] Balali, V., Zahraie, B., Roozbahani, A., A Comparison of AHP and PROMETHEE Family Decision Making Methods for Selection of Building Structural System, American Journal of Civil Engineering and Architecture, 2(5), (2014), 149-159.

[5] Golabchi, M., A Knowledge-Based Expert System for Selection of Appropriate Structural Systems for Large Spans, Asian Journal of Civil Engineering (Building and Housing), 9(2), (2008), 179-191.

[6] Balali, V., Mottaghi, A., Shoghli, O., Golabchi, M., Selection of Appropriate Material, Construction Technique, and Structural System of Bridges by Use of Multicriteria Decision-Making Method, Transportation Research Record: Journal of the Transportation Research Board, 2431, (2014), 79-87.

[7] Najafi, A., Karimpour, M. H., Ghaderi, M., Application of Fuzzy AHP Method to IOCG Prospectivity Mapping: A Case Study in Taherabad Prospecting Area, Eastern Iran, International journal of applied earth observation and geoinformation, 33, (2014), 142-154.

[8] Rajaeian, M. M., Cater-Steel, A., Lane, M., A Systematic Literature Review and Critical Assessment of Model-Driven Decision Support for IT Outsourcing, Decision Support Systems, 102, (2017], 42-56.

[9] Saaty, T. L., Decision Making with the Analytic Hierarchy Process, International journal of services sciences, 1(1), (2008), 83-98.

[10] Zeshui, X., Cuiping, W., A Consistency Improving Method in the Analytic Hierarchy Process, European Journal of Operational Research, 116(2), (1999), 443-449.

[11] Büyüközkan, G., Görener, A., Evaluation of Product Development Partners Using An Integrated AHP-VIKOR Model, Kybernetes, 44(2), (2015), 220-237.

[12] Opricovic, S., \& Tzeng, G. H., Compromise Solution by MCDM Methods: A Comparative Analysis of VIKOR and TOPSIS, European Journal of Operational Research, 156(2), (2004), 445-455. 